\title{
A comparison of the enzymological and biophysical properties of two distinct classes of dehydroquinase enzymes
}

\author{
Colin KLEANTHOUS, ${ }^{*} \dagger$ Ranjit DEKA, ${ }^{*}$ Ken DAVIS, $\$ \S$ Sharon M. KELLY, $\|$ Alan COOPER, $\uparrow$ \\ Stephen E. HARDING, $\ddagger$ Nicholas C. PRICE, $\|$ Alastair R. HAWKINS** and John R. COGGINS* \\ Departments of *Biochemistry and -Chemistry, University of Glasgow, Glasgow G12 8QQ, U.K., \\ †Department of Applied Biochemistry \& Food Science, University of Nottingham, Sutton Bonington LE12 5RD, U.K., \\ \|Department of Biological and Molecular Sciences, University of Stirling, Stirling FK9 4LA, U.K., \\ and **Department of Biochemistry and Genetics, The Medical School, The University, Newcastle upon Tyne NE2 4HH, U.K.
}

\begin{abstract}
This paper compares the biophysical and mechanistic properties of a typical type I dehydroquinase (DHQase), from the biosynthetic shikimate pathway of Escherichia coli, and a typical type II DHQase, from the quinate pathway of Aspergillus nidulans. C.d. shows that the two proteins have different secondary-structure compositions; the type I enzyme contains approx. $50 \% \alpha$-helix while the type II enzyme contains approx. $75 \% \alpha$-helix. The stability of the two types of DHQase was compared by denaturant-induced unfolding, as monitored by c.d., and by differential scanning calorimetry. The type II enzyme unfolds at concentrations of denaturant 4-fold greater than the type I and through a series of discrete transitions, while the type I enzyme unfolds in a single transition. These differences in conformational stability were also. evident from the calorimetric experiments which show that type I DHQase unfolds as a single co-operative dimer at $57^{\circ} \mathrm{C}$ whereas the type II enzyme unfolds above $82^{\circ} \mathrm{C}$ and through a series of transitions suggesting higher orders of structure than that seen for the type I enzyme. Sedimentation and $M_{\mathrm{r}}$ analysis of both proteins by analytical ultracentrifugation is consistent with the unfolding data. The type I DHQase exists predominantly as a dimer with $M_{\mathrm{r}}=46000 \pm 2000$ (a weighted average affected by the presence of monomer) and has a sedimentation coefficient $s^{0}{ }_{20, w}=4.12( \pm 0.08) \mathrm{S}$ whereas the type II enzyme is a dodecamer, weight-average $M_{\mathrm{r}}=190000 \pm 10000$ and has a sedimentation coefficient, $s^{0}{ }_{20, w}=9.96( \pm 0.21) \mathrm{S}$. Although both enzymes have reactive histidine residues in the active site and can be inactivated by diethyl pyrocarbonate, the possibility that these structurally dissimilar enzymes catalyse the same dehydration reaction by the same catalytic mechanism is deemed unlikely by three criteria: (1) they have very different $\mathrm{pH} / \log k_{\text {cat. }}$ profiles and pH optima; (2) imine intermediates, which are known to play a central role in the mechanism of type I enzymes, could not be detected (by borohydride reduction) in the type II enzyme; (3) unlike Schiff's base-forming type I enzymes, there are no conserved lysine residues in type II amino acid sequences.
\end{abstract}

\section{INTRODUCTION}

The enzyme dehydroquinase (3-dehydroquinate dehydratase; EC 4.2.1.10) catalyses the dehydration of 3-dehydroquinic acid to 3-dehydroshikimic acid and is a central step in two separate metabolic pathways, one involved in biosynthesis the other involved in catabolism [1,2] (Scheme 1). Biosynthetic dehydroquinase (bDHQase) is part of the shikimate pathway in microorganisms which is responsible for the biosynthesis of aromatic compounds, for example, the aromatic amino acids (Scheme 1). Catabolic dehydroquinase (cDHQase), on the other hand, is part of the quinate pathway of fungi and enables the organism to utilize quinate as a carbon source via the $\beta$-ketoadipate pathway (Scheme 1). In these fungi, bDHQase and cDHQase are encoded by genetic loci that are subject to distinct physiological and genetical controls. cDHQase in Aspergillus nidulans is inducible by the presence of quinate and is encoded by the $Q U T E$ gene, one of seven tightly linked genes comprising the quinic acid utilization gene cluster [3-8]. bDHQase, on the other hand, is constitutively produced, and is encoded by the complex AROM locus which specifies a pentafunctional polypeptide, which is active as a dimer (the arom protein) and catalyses steps two to six in the shikimate pathway [9-11]. Lamb et al. [12] have shown that the common metabolites 3-dehydroquinate and dehydro- shikimate leak from the arom protein at a rate comparable with the flux of metabolites through the shikimate pathway and can be utilized by the enzymes of both pathways. A similar fused polypeptide is also present in Neurospora crassa [13-15] and Saccharomyces cerevisiae [16] but, in prokaryotes, steps two to six in the shikimate pathway are catalysed by distinct monofunctional enzymes [17-21] that are constitutively expressed and are not required to aggregate for activity. Evidence from DNA sequence analysis has strongly suggested that the complex AROM locus arose by multiple gene fusions to generate the pentafunctional arom polypeptide $[22,23]$. Recently it has been shown, by site-directed mutagenesis of the $A$. nidulans AROM locus, that some of the arom polypeptide (including the bDHQase domain) can fold and function in Escherichia coli as monofunctional enzymes [24]. In addition, a study of protein sequences deduced from DNA sequence data has shown that the quinate dehydrogenase enzyme of the quinic acid utilization pathway and the shikimate dehydrogenase enzyme of the shikimate pathway have evolved from a common ancestral sequence $[5,19]$. Conversely, the comparison of bDHQase and cDHQase enzyme sequences has led to the proposal that the two enzymes arose by convergent evolution $[23,25]$.

Until recently the bDHQases (typified by the monofunctional $E$. coli enzyme) and the cDHQases (typified by the fungal quinic

\footnotetext{
Abbreviations used: DHQase, dehydroquinase; cDHQase, catabolic dehydroquinase; bDHQase, biosynthetic dehydroquinase; DEP, diethyl pyrocarbonate.

$\dagger$ To whom correspondence should be addressed, at: Molecular \& Microbiology Sector, School of Biological Sciences, University of East Anglia, Norwich NR4 7TJ, U.K.

$\S$ Present address: Biophysics Laboratories, Portsmouth Polytechnic, Whiteswan Road, Portsmouth PO1 2DT, U.K.
} 


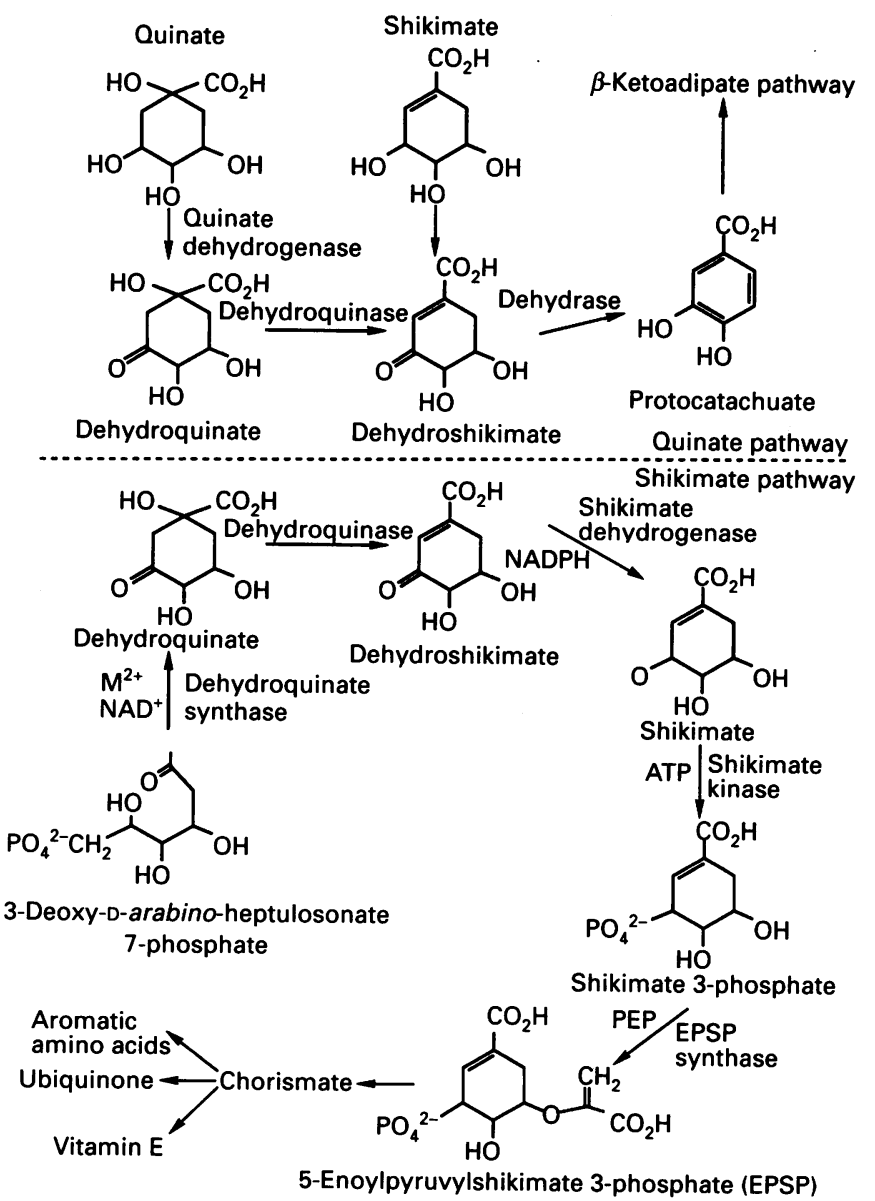

Scheme 1. Position of DHQase enzymes in the biosynthetic shikimate pathway and the catabolic quinate pathway.

acid utilization enzymes) have been distinguished by clear differences in subunit size, oligomeric structure and their susceptibility towards heat denaturation. However, two lines of evidence now suggest that this classification does not adequately describe the classes of DHQase and the pathways in which they participate. Firstly, White et al. [26] have identified a single DHQase enzyme in Streptomyces coelicolor which, although likely to be part of the shikimate pathway, has the properties and $N$-terminal sequence usually found in catabolic type enzymes. Secondly, Garbe et al. [27] have isolated a gene (designated aroQ) from Mycobacterium tuberculosis that encodes a heat-stable DHQase enzyme with a deduced protein sequence that shows close similarity to the fungal $\mathrm{cDHQases}$. The aro $Q$ gene was isolated on a $3.4 \mathrm{~kb}$ fragment of DNA which also contains the aro $B$ gene (encoding dehydroquinate synthase; see Scheme 1), with the $3^{\prime}$ terminal sequence of $\operatorname{aroB}$ (ATGA) also encoding the AUG translational start codon of aro $Q$. These observations strongly suggest that this CDHQase-like enzyme functions in the shikimate pathway of $M$. tuberculosis.

Thus it seems that even catabolic-type enzymes can function in a biosynthetic context. White et al. [26] have suggested type I (biosynthetic-like) and type II (catabolic-like) DHQases as a more appropriate nomenclature. Given this added complexity and in order to define the differences between the two classes of DHQase more precisely, we have subjected the E. coli aroDencoded (type I) and $A$. nidulans $Q U T E$-encoded (type II) DHQases to a comparative biochemical and biophysical characterization. The data presented in this paper firmly establish the criteria for the classification of type I and type II DHQases and further support the hypothesis of Garbe et al. [27] based on protein sequence comparisons that the type I and type II DHQases are phylogenetically and mechanistically distinct.

\section{MATERIALS AND METHODS}

\section{Reagents}

All the reagents except those specified below were obtained from: BDH Ltd., Thornliebank, Glasgow, U.K.; Boehringer Mannheim U.K., Lewes, East Sussex, U.K.; Sigma Chemical Co., Poole, Dorset, U.K.; Aldrich Chemical Co. Ltd., Gillingham, Dorset, U.K. DEAE-Sephacel and Sephacryl-S200 (superfine grade) were obtained from Pharmacia Ltd., Central Milton Keynes, Bucks, U.K., and Bio-gel HTP (hydroxyapatite) from Bio-Rad Laboratories Ltd., Hemel Hempstead, Herts., U.K. Guanidine hydrochloride was obtained from Gibco-BRL, Uxbridge, Middx., U.K. Ammonium dehydroquinate was prepared by the method of Grewe \& Haendler [28].

\section{Protein purification}

Type I DHQase was purified from an overexpressing strain of E. coli as originally described by Chaudhuri et al. [29]. Type II DHQase from $A$. nidulans was overexpressed in $E$. coli and purified as described by Beri et al. [30]. There is no contamination from host type I DHQase using this strategy because the extracts are first heat-treated $\left(70^{\circ} \mathrm{C}\right.$ for $\left.15 \mathrm{~min}\right)$, which denatures all the type I enzyme but does not affect the eukaryotic type II enzyme.

\section{Protein determinations}

Protein content was determined by amino acid analysis in conjunction with the known compositions of the proteins.

\section{C.d. and guanidine hydrochloride denaturation}

Conditions for c.d. analysis of both DHQases were as described for the type I enzyme by Kleanthous et al. [31], except that they were recorded in $0.05 \mathrm{M}$-Tris/acetate, $\mathrm{pH} 7.0$ rather than potassium phosphate, $\mathrm{pH}$ 7.0. The determination of secondarystructure content was undertaken by analysis of the spectrum from $190 \mathrm{~nm}$ to $240 \mathrm{~nm}$ at $1 \mathrm{~nm}$ intervals using the CONTIN procedure [32]. Denaturation curves were obtained by monitoring the loss of $[\theta]_{225}$ signal as a function of guanidine hydrochloride concentration at $\mathrm{pH} 7.0$ (high concentrations of guanidine hydrochloride do not affect the apparent $\mathrm{pH}$ of the buffer). Samples were incubated for $24 \mathrm{~h}$ before measurements were taken to ensure equilibration. The accuracy of the various concentrations of guanidine hydrochloride used was checked by determination of their refractive index [33]. The activity of each of the enzymes was also analysed as a function of guanidine hydrochloride concentration. Each enzyme was incubated in a variety of guanidine hydrochloride concentrations in either $0.05 \mathrm{M}$ potassium phosphate buffer, $\mathrm{pH} 7.0$ (type I) or $0.05 \mathrm{M}$-Tris/ acetate buffer, pH 7.0 (type II) for at least $24 \mathrm{~h}$ at room temperature and then assayed in the same buffer containing the same guanidine hydrochloride concentration.

\section{Differential scanning calorimetry}

These experiments were performed using a Microcal MC-2D calorimeter, as described by Kleanthous et al. [31]. Type I experiments were conducted in potassium phosphate buffer and type II experiments in $0.05 \mathrm{M}$-Tris/acetate, $\mathrm{pH}$ 7.0. Typical protein concentrations were $0.3 \mathrm{mg} / \mathrm{ml}$ for type I and $1-2 \mathrm{mg} / \mathrm{ml}$ for type II.

\section{Analytical ultracentrifugation}

Sedimentation velocity. Sedimentation-velocity experiments were performed in an MSE Centriscan 75 analytical ultra- 
centrifuge equipped with scanning Schlieren and scanning absorption optics. All experiments were performed at $20^{\circ} \mathrm{C}$ at rotor speeds of $47000-50000 \mathrm{rev} . / \mathrm{min}$ [type I (E. coli)] or $35000-41000 \mathrm{rev} . / \mathrm{min}$ [type II (A. nidulans)]. Schlieren measurements were at a wavelength of $546 \mathrm{~nm}$, absorption measurements at $280 \mathrm{~nm}$. Five to ten scans were used in determining each value of the sedimentation coefficient at a particular concentration $c$ (corrected for radial dilution). The sedimentation data were captured using a Cherry digitizing Tablet interfaced to an Apple IIE computer, which evaluated the sedimentation coefficient and the radial dilution correction factor for concentration.

All sedimentation coefficients, $s_{c(T, \mathrm{~b})}$ (the subscripts refer to solvent $\mathrm{b}$, of temperature $T$, and at finite concentrations $c$ ), were corrected to standard conditions with water as solvent, at $20^{\circ} \mathrm{C}$ (for example, see van Holde [34]:

$$
s_{c(20, \mathrm{w})}=\frac{(1-\bar{v} \rho)_{20, \mathrm{w}}}{(1-\bar{v} \rho)_{\mathrm{T}, \mathrm{b}}} \times \frac{\eta_{\mathrm{T}, \mathrm{b}}}{\eta_{20, \mathrm{w}}} \times s_{c(T, \mathrm{~b})}
$$

$\eta$ is the solvent viscosity, $\bar{v}$, the partial specific volume and $\rho$, the solution density. Partial specific volumes of $0.746 \mathrm{ml} / \mathrm{g}$ (type I) and $0.745 \mathrm{ml} / \mathrm{g}$ (type II) were calculated from published amino acid sequence data (refs [18] and [35] for type I and ref. [25] for type II) according to the Traube rule [36]. Use of solution densities for each concentration is rather difficult, tedious and wasteful of material, and so we follow the common procedure of using solvent densities. This has no effect on the value of $s_{c(20, \mathrm{w})}$ extrapolated to infinite dilution $\left(s^{0}{ }_{20, w}\right)$ and a simple correction exists [37] for the concentration-dependence regression parameter, $k_{\mathrm{s}}$, in the relation:

$$
s_{c(20, w)}=s_{(20, w)}^{0}\left(1-k_{\mathrm{s}} c\right)
$$

Sedimentation-equilibrium measurements. Sedimentation-equilibrium experiments were performed using a Beckman model E analytical ultracentrifuge equipped with Rayleigh interferometric optics, a $5 \mathrm{~mW} \mathrm{He} / \mathrm{Ne}$ laser light source and an RTIC temperature-measuring system set for $20.0^{\circ} \mathrm{C}$ (type I) and $23.2^{\circ} \mathrm{C}$ (type II). The 'low' or 'intermediate' speed method was used where the speed is sufficiently low to allow adequate resolution of the fringes near the cell base [38]. In this method the concentration at the air/solution meniscus remains finite and can be found by mathematical manipulation of the fringe data [38].

Before use, all samples were dialysed for at least $24 \mathrm{~h}$ against $0.05 \mathrm{M}$-potassium phosphate, $\mathrm{pH} 7.0$, type I or $0.05 \mathrm{M}$-Tris/ $\mathrm{HCl}, \mathrm{pH} 7.0$, type II respectively. Determinations were made in $30 \mathrm{~mm}$ optical path length cells at a rotor speed of $10082 \mathrm{rev} . /$ min (type I) and $9141 \mathrm{rev} . / \mathrm{min}$ (type II). The lowest possible loading concentrations (approx. $0.50 \mathrm{mg} / \mathrm{ml}$ for the type I and approx. $0.20 \mathrm{mg} / \mathrm{ml}$ for the type II) were chosen in both cases.

Data from the Rayleigh interference patterns were captured off-line on an LKB Ultroscan XL two-dimensional laser densitometer scanner interfaced to an Olivetti PC. Fringe concentration versus radial displacement plots were obtained using the UCSD PASCAL routine 'ANALYSE2' [39]. These data were then transferred via the joint UK Computer network (JANET) for full analysis on the mainframe IBM 3081/B at Cambridge. Whole-cell weight-average, $\boldsymbol{M}_{\mathrm{r}}^{0}$ values were obtained by using the limiting value at the cell base of a directly determinable point average $M_{\mathrm{r}}^{*}$ [38]. Using this procedure, an independent estimate for the initial concentration was not required. Point weight-average $M_{\mathrm{r}}$ values were obtained by using sliding-strip quadratic fits to the observed fringe data [40].

\section{Steady-state kinetics}

Enzymic activity for both the type I and type II DHQases was measured spectrophotometrically by measuring the formation of product, dehydroshikimate, at $234 \mathrm{~nm}$ $\left(\epsilon=1.2 \times 10^{4}\right.$ litres $\left.\cdot \mathrm{mol}^{-1} \cdot \mathrm{cm}^{-1}\right)$ in a final volume of $1 \mathrm{ml}$ and at $25^{\circ} \mathrm{C}$ as described by Kleanthous et al. [41]. Different buffers were used for each of the DHQase enzymes because, in general, buffers which are appropriate for one are inhibitors for the other (see the Results and discussion section). As a result, $0.05 \mathrm{M}$ potassium phosphate, $\mathrm{pH} 7.0$, was used for the $E$. coli type I

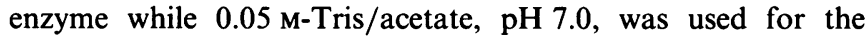
$A$. nidulans type II enzyme. Under these conditions there is approximately a 10 -fold difference in the $K_{\mathrm{m}}$ value for the substrate between the type I and type II enzymes. The concentration of dehydroquinate used for routine assays (such as monitoring purification of each enzyme) of the type I and type II enzymes was $100 \mu \mathrm{M}$ and $1000 \mu \mathrm{M}$ respectively. These concentrations represent approx. 7-fold $K_{\mathrm{m}}$ for the two enzymes.

The $\mathrm{pH}$-dependence of $V_{\max }$ for the $E$. coli type I enzyme has already been described [29]. The $\mathrm{pH}$-dependence of $V_{\max }$ for the type II enzyme has yet to be reported and so was determined in the broad $\mathrm{pH}$ range buffer bistrispropane/acetate (see the Results and discussion section). $V_{\max }$. values were obtained directly from curves fitted to the Michaelis-Menten equation and each curve was composed of 14-16 substrate concentrations, each of which was measured in triplicate.

\section{Borohydride reduction of imine intermediates}

The borohydride reduction of $E$. coli type I DHQase has already been described [31,35]. Attempted borohydride reductions of $A$. nidulans type II DHQase were performed essentially as described by Kleanthous et al. [31] but in a variety of different buffers, including Tris/acetate, bistrispropane/acetate and potassium phosphate, all at a concentration of $0.05 \mathrm{M}$, and a range of $\mathrm{pH}$ values ( $\mathrm{pH} 7-9)$ and using a range of substrate concentrations (1-5 mM).

\section{Diethyl pyrocarbonate (DEP) inactivation}

Inactivation by DEP ( $1 \mathrm{mM}$ ) was performed in potassium phosphate buffer $\left(0.05 \mathrm{M}, \mathrm{pH} 6.0,25^{\circ} \mathrm{C}\right)$ for the type I enzyme $(2.6 \mu \mathrm{M}$ final protein concentration) and sodium bicarbonate buffer $\left(0.05 \mathrm{M}, \mathrm{pH} 8.5,25^{\circ} \mathrm{C}\right)$ for the type II enzyme $(7.5 \mu \mathrm{M}$ final protein concentration). Although the type II enzyme is normally assayed in tris-based buffers, these cannot be used in conjunction with DEP. Bicarbonate buffer was chosen because, although it raises the $K_{\mathrm{m}}$ for the substrate 4-fold (compared with bistrispropane/acetate at the same $\mathrm{pH}), V_{\text {max. }}$ remains relatively unaffected (results not shown). At regular time-intervals, samples were removed from each incubation, quenched in imidazole buffer (10 mM, pH 7.0) and diluted into a standard assay, as described above, to determine the residual activity. Substrate protection experiments involved adding dehydroquinate at a concentration 5-fold in excess of the $K_{\mathrm{m}}$ value before the addition of DEP to each enzyme.

\section{RESULTS AND DISCUSSION}

\section{Secondary-structure analysis}

The secondary-structure composition of both proteins was estimated by c.d. (Fig. 1). The secondary-structure content for the type I enzyme from $E$. coli (in phosphate buffer) has already been described [31] but was repeated, for the purposes of comparison with the type II enzyme, and both spectra were recorded in Tris/acetate buffer. Estimates of the secondarystructure composition of type I DHQase obtained in this study show good agreement with those previously observed [31]; the values obtained in this study were $50 \% \alpha$-helix, $25 \% \beta$-sheet and $25 \%$ remainder (compared with $45 \% \alpha$-helix, $28 \% \beta$-sheet and $27 \%$ remainder from ref. [31]). The type II enzyme, for which there is no published secondary-structure analysis, shows signifi- 


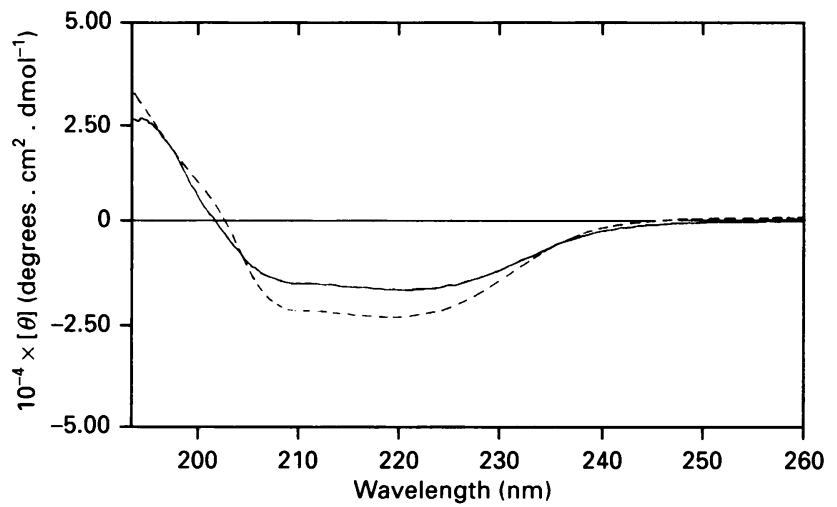

Fig. 1. Far-u.v. c.d. spectra for type I and type II DHQases

Both spectra were recorded in Tris/acetate buffer $(0.05 \mathrm{M}, \mathrm{pH} 7.0)$ at $20^{\circ} \mathrm{C}$. The solid line is the spectrum for type I ( $E$. coli $)$ DHQase $(0.20 \mathrm{mg} / \mathrm{ml})$ and the dashed line is the spectrum for type II (A. nidulans) DHQase $(0.20 \mathrm{mg} / \mathrm{ml})$.

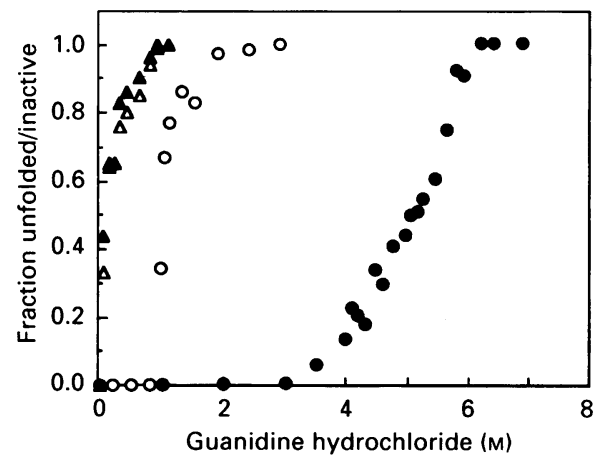

Fig. 2. Effects of guanidine hydrochloride on the secondary structure (circles) and activity (triangles) of DHQase enzymes, plotted as a function of the total change observed

Denaturation of the DHQases by guanidine hydrochloride was monitored by c.d. $\left([\theta]_{225 \mathrm{~nm}}\right)$ in Tris/acetate buffer $(0.05 \mathrm{M}, \mathrm{pH} 7.0)$. $\bigcirc$, Type I ( $E$. coli) DHQase;, type II ( $A$. nidulans) DHQase. The effect of guanidine hydrochloride on activity was determined in potassium phosphate $(0.05 \mathrm{M}, \mathrm{pH} 7.0)$ for the type I enzyme $(\triangle)$ and Tris/acetate $(0.05 \mathrm{M}, \mathrm{pH} 7.0)$ for the type II enzyme $(\boldsymbol{\Delta})$.

cantly greater $\alpha$-helical content (approx. $75 \%$ ) than the type I enzyme and the remainder is predominantly $\beta$-sheet. This estimate is derived using the CONTIN procedure of Provencher \& Glockner [32]. Attempts to analyse the c.d. spectrum using the method of Chang et al. [42] did not yield a satisfactory fit to the experimental data with the constrained or free fitting procedures. Similarly, the method of Siegel et al. [43] gave an unreasonably high content of $\alpha$-helix (98\%).

\section{Chemical and thermal denaturation of the DHQases}

Denaturation and inhibition by guanidine hydrochloride. Resistance of catabolic type II DHQases towards chemical and heat denaturation has been reported previously [44,3] but a more extensive biophysical study has not been possible because of the limited quantities of protein available. The $Q U T E$ gene encoding the $A$. nidulans type II DHQase has now been overexpressed, first in $A$. nidulans and, more recently, in $E$. coli [30 and 24 respectively]. Moreover, a comparison with the type I enzyme from $E$. coli, which has also been overexpressed [18], has not been published. The present analysis has used c.d. to monitor the guanidine hydrochloride denaturation of both proteins (Fig. 2). The effect of denaturant on the activity of both proteins has also been investigated (Fig. 2). The results from these studies are summarized below.

(1) The guanidine hydrochloride denaturation curve of the type I enzyme in Tris/acetate buffer is very similar to that seen in phosphate buffer [31]; the absence of discontinuities in the unfolding transition suggests that the dimer unfolds in a single co-operative step and [guanidine hydrochloride] $]_{1 / 2}=1.3 \mathrm{M}$ (cf. $1.2 \mathrm{M}$ in phosphate buffer). The co-operativity of unfolding transitions has been discussed by Creighton [45].

(2) The guanidine hydrochloride denaturation of the type II enzyme is very different from that of the type I. There is a 4-fold increase in the concentration of denaturant required to unfold the type II ([guanidine hydrochloride $]_{1 / 2}=5.2 \mathrm{M}$ ) compared with the type I enzyme and the destruction of secondary structure does not occur in a single step but takes place over a broad range of guanidine hydrochloride concentrations. The discontinuities of the type II denaturation profile may indicate as many as three transitions, the first between 3 and $4 \mathrm{M}$, the second between 4 and $5 \mathrm{M}$ and the third between 5 and $6 \mathrm{M}$.

(3) While the denaturation of both proteins is very different, the effect of guanidine hydrochloride on the activity of both enzymes is remarkably similar (Fig. 2). Some $90 \%$ of DHQase activity is lost in both enzymes at $0.7 \mathrm{M}$-guanidine hydrochloride, a concentration at which both retain $100 \%$ of their native secondary structure. E. coli type I DHQase can be refolded to yield active enzyme from denaturing concentrations of guanidine hydrochloride by gel filtration [46] and by dilution. Type II DHQase activity can only be recovered from non-denaturing concentrations of guanidine hydrochloride $(0-3 \mathrm{M})$. As the fraction of unfolded type II protein increases, the recoverable activity decreases to a point where, at $6 \mathrm{M}$-guanidine hydrochloride, no activity could be recovered by dilution (results not shown).

Differential scanning calorimetry. Type II DHQase is resistant to thermal denaturation, and this property has aided its extraction from a number of sources since a heat step can be included in the purification scheme $[3,26,44]$. We have analysed the thermal denaturation isotherms for both types of DHQase by differential scanning calorimetry in order that quantitative comparisons can be made between them, such as the number of thermal transitions, the temperatures at which they occur and the reversibility of the process. Thermal denaturation profiles for type I and type II DHQases at $\mathrm{pH} 7.0$ are shown in Fig. 3 and the results are summarized below.

(1) The thermal denaturation of type I DHQase in phosphate buffer $\mathrm{pH} 7.0$ shows a single isotherm $\left(T_{\mathrm{m}}=57^{\circ} \mathrm{C}\right)$ where the cooperative unit of unfolding is the protein dimer.

(2) Thermal denaturation of the type II enzyme involves at least three transitions. The first is a broad shoulder at approx. $82^{\circ} \mathrm{C}$, the second is a sharp doublet at $86^{\circ} \mathrm{C}$ and the final transition occurs at $95^{\circ} \mathrm{C}$.

(3) Both enzymes are precipitated after thermal denaturation and the process is irreversible, at these protein concentrations and under the conditions described.

The chemical and thermal denaturation profiles for the two types of DHQase are consistent with very different quaternary structures, and this is mirrored by analytical ultracentrifugation experiments (see below). The denaturation profile of the type I enzyme is relatively simple and occurs in a single, co-operative step where the unit of unfolding is dominated by the protein dimer [31]. Several transitions are observed in the type II enzyme which indicate either discrete unfolding of domains or, more likely, the destruction of an aggregated structure through intermediate oligomeric forms.

Interestingly, a highly stabilized form of $E$. coli (type I) DHQase [approximating that of the $A$. nidulans (type II) enzyme] is produced on chemical reduction of ligand at its active site 


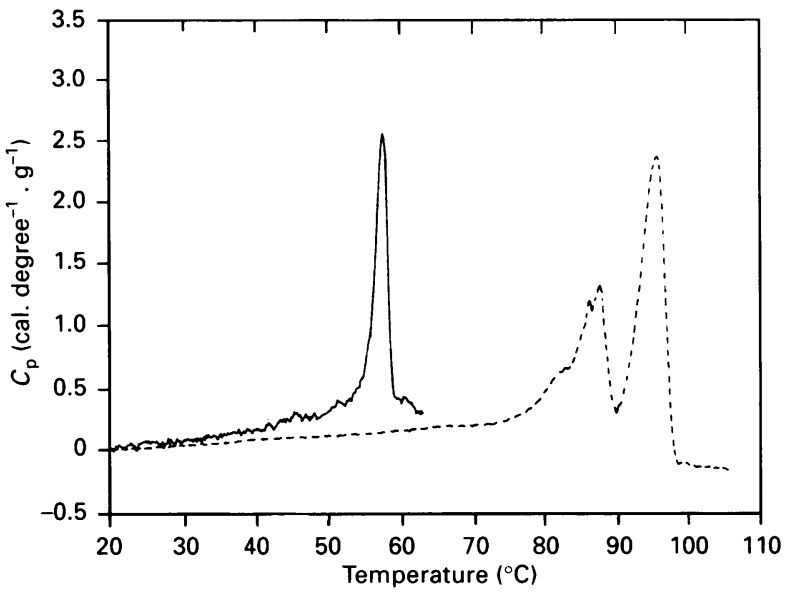

Fig. 3. Thermal denaturation of DHQases monitored by differential scanning calorimetry showing excess specific heat $\left(C_{\mathrm{p}}\right)$ versus temperature

Type I ( $E$. coli) enzyme (solid line) is in potassium phosphate buffer $(0.05 \mathrm{M}, \mathrm{pH} 7.0)$ and at a concentration of $0.3 \mathrm{mg} / \mathrm{ml}$. Type II $(A$. nidulans) enzyme (dashed line) is in Tris/acetate buffer $(0.05 \mathrm{M}$, $\mathrm{pH} 7.0$ ) and at a concentration of $2.1 \mathrm{mg} / \mathrm{ml}$.
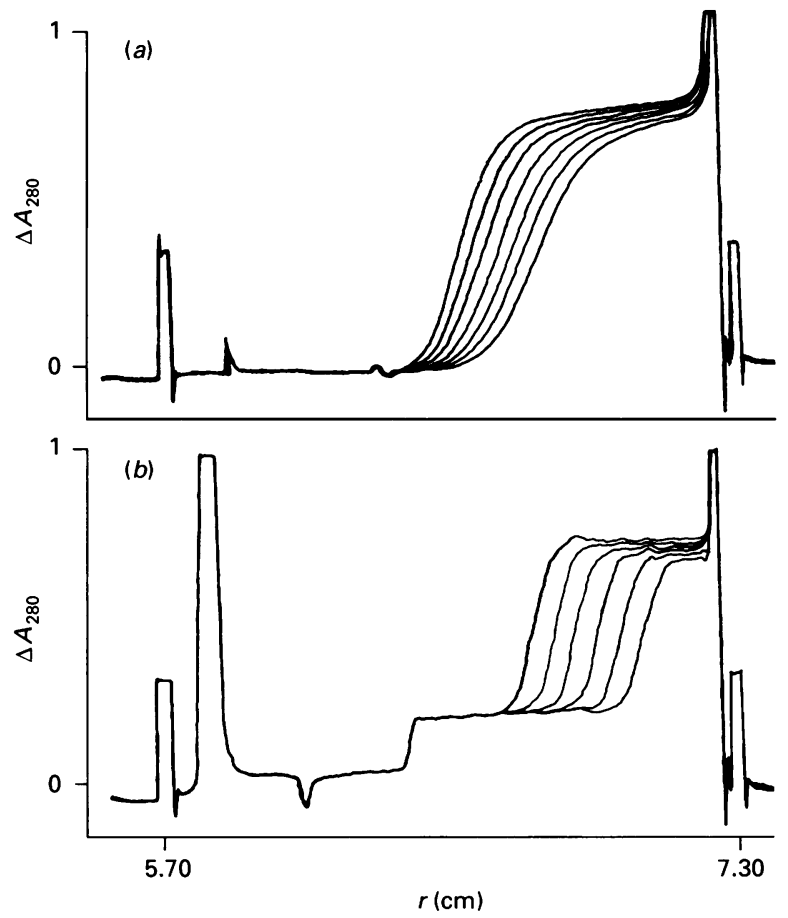

Fig. 4. Sedimentation profiles for (a) type I (E. coli) and (b) type II (A. nidulans) DHQases

Scanning absorption optics were used with the monochromator set at $280 \mathrm{~nm}$. Rotor temperature was $20.0^{\circ} \mathrm{C}$. The direction of sedimentation is from left to right. In $(a)$ the rotor speed was $50000 \mathrm{rev}$./ min, the scan interval was every $8 \mathrm{~min}$ and the initial cell loading concentration was $0.90 \mathrm{mg} / \mathrm{ml}$. In $(b)$ the rotor speed was $35000 \mathrm{rev}$./ $\mathrm{min}$, the scan interval was every $12 \mathrm{~min}$ and the initial loading concentration was $0.95 \mathrm{mg} / \mathrm{ml}$.

without any change in quaternary structure [31]. In this case the dramatic stabilization is a consequence of the bound ligand promoting the native structure of the enzyme relative to the unfolded state.
Table 1. Hydrodynamic data for type I and type II DHQases at pH 7.0

See the text for details of the listed parameters. The ' \pm ' values of the weight-average $M_{\mathrm{r}}$ data represent the precision with which these data have been obtained.

\begin{tabular}{lcc}
\hline & $\begin{array}{c}\text { Type I } \\
(E . \text { coli })\end{array}$ & $\begin{array}{c}\text { Type II } \\
(\text { A. nidulans })\end{array}$ \\
\hline $10^{13} \times s^{0}{ }_{20 . w}(\mathrm{~s})$ & $4.12 \pm 0.08$ & $9.96 \pm 0.21$ \\
$k_{\mathrm{s}}(\mathrm{ml} / \mathrm{g})$ & $35.7 \pm 8.4$ & $64.8 \pm 12.8$ \\
$\bar{v}(\mathrm{ml} / \mathrm{g})$ & 0.746 & 0.745 \\
Subunit $M_{\mathrm{r}}$ & 27466 & 16505 \\
$M_{\mathrm{r}}^{0}$ & $46000 \pm 2000$ & $190000 \pm 10000$ \\
$M_{\mathrm{r}}$ (cell meniscus) & $44000 \pm 3000$ & - \\
$M_{\mathrm{r}}$ (cell base) & $53000 \pm 3000$ & $200000 \pm 10000$ \\
$M_{\mathrm{r}}(J=0)$ & $30000 \pm 5000$ & - \\
Number of subunits & 2 & 12
\end{tabular}

Table 2. Kinetic constants for type I and type II DHQases at pH 7.0 and $25^{\circ} \mathrm{C}$

\begin{tabular}{lcc}
\hline & $\begin{array}{c}\text { Type I } \\
(E . \text { coli })^{*}\end{array}$ & $\begin{array}{c}\text { Type II } \\
(\text { A. nidulans }) \dagger\end{array}$ \\
\hline $\begin{array}{l}\text { Specific activity } \ddagger \\
\text { (units } / \mathrm{mg})\end{array}$ & 350 & 3200 \\
$k_{\text {cat. }}\left(\mathrm{s}^{-1}\right)$ & 135 & 1300 \\
$K_{\mathrm{m}}(\mu \mathrm{M})$ & 16 & 150 \\
$k_{\text {cat. }} / K_{\mathrm{m}}\left(\mathrm{s}^{-1} \cdot \mathrm{M}^{-1}\right)$ & $8.4 \times 10^{6}$ & $8.7 \times 10^{6}$
\end{tabular}

* Values determined in potassium phosphate buffer $(0.05 \mathrm{M}, \mathrm{pH} 7.0)$.

$\dagger$ Values determined in Tris/acetate buffer $(0.05 \mathrm{M}, \mathrm{pH} 7.0)$.

$\ddagger$ Protein concentrations were determined by amino acid analysis.

\section{Oligomeric structure}

Homogeneity. Type I and type II DHQases have been purified to homogeneity $[29,30]$ and the sedimentation data (examples of which are shown in Fig. 4) are consistent with such a homogeneous monodispersed system. However, there is evidence of heterogeneity due to subunit association-dissociation (see below) which would still result in such sedimentation diagrams [47].

$M_{\mathrm{r}}$ values and sedimentation coefficients. Both type I ( $E$. coli) and type II ( $A$. nidulans) DHQases have been cloned and sequenced [18, 35 and 25 respectively] and so the subunit $M_{\mathrm{r}}$ values are known (Table 1). The oligomeric structures for both proteins were estimated by determinations of the weight-average $M_{\mathrm{r}}$ values by sedimentation equilibrium. In Table 1 four types of weight-average $M_{\mathrm{r}}$ are given: (i) the weight average over the whole distribution of solute within the ultracentrifuge cell, $M_{\mathrm{r}}^{0}$; (ii) the point weight average at the solution/air meniscus, $M_{\mathrm{r}}$ $(\xi=0)$, where $\xi$ is a normalized radial displacement squared parameter, normalized so it has a value of 0 at the meniscus and 1 at the base; (iii) the point weight average at the cell base, $M_{\mathrm{r}}$ $(\xi=1)$; (iv) the point-average $M_{\mathrm{r}}$ extrapolated to zero concentration, $M_{\mathrm{r}}(J=0)$ (but only for the type I enzyme; for type II the form of the extrapolation was more difficult to assess). $J$ is the concentration expressed in absolute fringe displacement units [proportional to the weight concentration, $c(\mathrm{~g} / \mathrm{ml})$ ].

The results from the sedimentation-velocity and sedimentation-equilibrium experiments are summarized below.

(1) The 'whole-distribution' weight-average $M_{\mathrm{r}}$ for type I does not precisely correspond to a simple dimer, for which the expected average $M_{\mathrm{r}}$ is 55000 . The value of $46000 \pm 2000$ suggests that the dimer is in equilibrium with its monomer subunits. This is 
confirmed from point-average $M_{\mathrm{r}}$ plots, and some of these data are represented in Table 1 . The point-average $M_{\mathrm{r}}$ of the type I enzyme is dependent on the radial position in the cell, with $M_{\mathrm{r}}$ at the cell base approximating the value for the dimer (55000). Interestingly, although performing an extrapolation to zero concentration is difficult, it appears that the $J=0$ (i.e. $c=0$ ) value is consistent with the monomer value (27466; Table 1) as might be expected.

(2) The whole-distribution weight-average $M_{\mathrm{r}}$ of $190000 \pm$ 10000 for $A$. nidulans type II DHQase (Table 1) is similar to that found for the same enzyme by gel-filtration experiments [3] and by analytical ultracentrifugation for the $N$. crassa type II DHQase [44], both of which gave a value for $M_{\mathrm{r}}$ of approx. 220000 .

(3) The native weight-average $M_{\mathrm{r}}$ for the type II enzyme is some 5-fold higher than for the type I enzyme; its sedimentation coefficient is some 2.5 -fold greater.

(4) The type II enzyme is likely to be a dodecamer under the conditions used in these experiments (predicted $M_{\mathrm{r}}$ for the dodecamer is 198000), but is likely to adopt other smaller association-product structures since both the sedimentation coefficient and weight-average $M_{\mathrm{r}}$ are dependent on protein concentration. This is also consistent with the denaturation data which showed that the type II enzyme was denatured (whether by guanidine hydrochloride or heat) through a series of transitions.

(5) The $s^{0}{ }_{20, w}$ values obtained for both type I and type II are comparable, for the $M_{\mathrm{r}}$ values given, with those expected for a globular macromolecule, based on values for other proteins [48].

\section{Steady-state parameters}

The two types of DHQase are easily distinguished by their kinetic parameters (Table 2). The specific activity for the type II DHQase is almost an order of magnitude greater than that for the type I, a difference which mirrors the 10-fold difference in the turnover numbers for both enzymes. Nevertheless, the specificity constants for both enzymes (at this $\mathrm{pH}$ and temperature) are surprisingly similar and this is explained by a 10 -fold increase in $K_{\mathrm{m}}{ }^{\mathrm{DHQ}}$ for the type II enzyme compared with the type I. These values are not meant to imply that all type I or type II enzymes from different sources will behave exactly in this fashion, but from our own experiences with these and related enzymes these values are in general agreement with other type I and type II enzymes.

One complication that arises when making these comparisons is the nature of the buffer used for each enzyme. For example, anions such as chloride or acetate are competitive inhibitors of the type I enzyme from $E$. coli [29] and so Tris/ $\mathrm{HCl}$ and Tris/acetate buffers are to be avoided when assaying this enzyme (although these buffers were used in some biophysical experiments for the purposes of comparison with the type II enzyme). On the other hand, potassium phosphate, the buffer used for assaying the type I enzyme, is a competitive inhibitor of the type II enzyme from $A$. nidulans $\left(K_{\mathrm{i}}=10 \mathrm{~mm} ; \mathrm{R}\right.$. Deka, unpublished work) whereas acetate and chloride are not. As a result, a number of buffers should be tried when assaying crude extracts of an organism with an unknown DHQase type.

\section{Mechanistic comparisons of type I and type II DHQases}

Schiff's base intermediates. The mechanism of type I DHQase from $E$. coli and the type I-like domain of the pentafunctional protein of $N$. crassa both involve Schiff's base intermediates [35]. We have attempted to inactivate the type II enzyme from $A$. nidulans, in the presence of a substrate/product equilibrium mixture, with sodium borohydride as has already been described for the $E$. coli enzyme [31,35]. Inactivation would indicate the formation of an imine intermediate in the mechanism of the type II enzyme. However, we have been unable to demonstrate

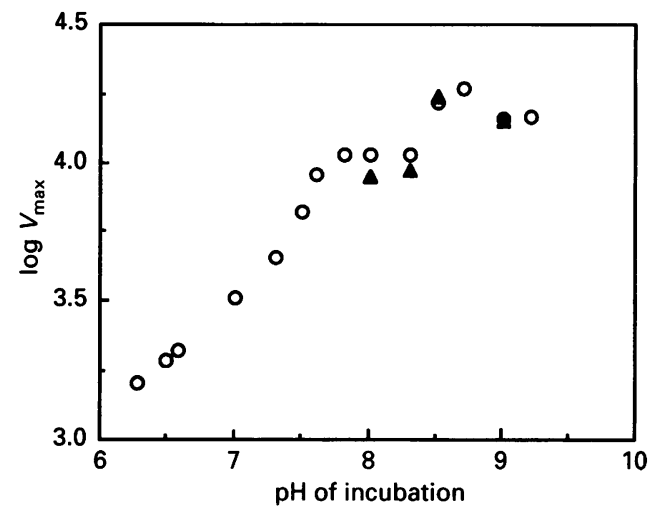

Fig. 5. Effect of pH on maximal velocity of type II ( $A$. nidulans) DHQase

All assays were conducted in bistrispropane $(0.05 \mathrm{M})$ at $25^{\circ} \mathrm{C}$ and in triplicate as described in the Experimental section. The circles show the results from a single experiment and the triangles are repeats of particular $\mathrm{pH}$ points.

substrate/product-associated borohydride inactivation of the $A$. nidulans type II enzyme at several $\mathrm{pH}$ values $(\mathrm{pH} 7-8.5)$, at a range of protein concentrations and in a variety of buffers (such as Tris/acetate, bistrispropane/acetate and even dilute phosphate buffer). Moreover, we have also tried the hydrophobic reagent cyanoborohydride without success. The absence of borohydride and cyanoborohydride reduction does not prove that the type II enzyme from $A$. nidulans does not function by a Schiff's base mechanism, but we believe that other circumstantial evidence, most notably sequence comparisons with other type II enzymes [27], lends support to this hypothesis.

pH-dependence of $\boldsymbol{V}_{\max }$. It is frequently observed that mechanistically important amino acid side chains ionize at $\mathrm{pH}$ values relevant to the activity of the enzyme. The $\mathrm{pH}$-dependence of $V_{\max }$ for the $E$. coli type I enzyme has already been reported [29]. The enzyme shows a simple dependence of $V_{\text {max. }}$ on $\mathrm{pH}$, consistent with the presence of a single ionizing group at the active site with the $\mathrm{p} K_{\mathrm{a}}$ of 6.1. $V_{\max }$ for the type I enzyme is maximal at $\mathrm{pH} 6.8$ and remains almost unchanged up to $\mathrm{pH}$ 9.0. The dependence of $V_{\max }$ on $\mathrm{pH}$ for a type II enzyme has not been reported previously and so it was determined for the purposes of comparison with the type I enzyme.

A problem was encountered, however, in preliminary experiments aimed at identifying appropriate buffer systems for this study. Most of the common buffers used in such studies (for example, those used in the study of the $E$. coli type I enzyme [29]) were all found to be inhibitors of the type II DHQase from $A$. nidulans (R. Deka, unpublished work). These included phosphate- (a competitive inhibitor), citrate- (for which no enzymic activity could be detected under standard assay conditions) and bicarbonate- (also a competitive inhibitor) based buffers which were all found to be inappropriate for this study. Finally, we opted for the single broad-range buffer bistrispropane which did not alter the kinetic parameters of the enzyme (relative Tris/acetate under standard assay conditions) but could only be used over the narrow $\mathrm{pH}$ range 6-9. The dependence of $V_{\max }$ on $\mathrm{pH}$ for the type II enzyme from $A$. nidulans in bistrispropane is shown in Fig. 5. The results are summarized below.

(1) In contrast with the type I enzyme of $E$. coli, $V_{\max }$ is maximal for the type II enzyme at $\mathrm{pH}$ 8.5-9.0.

(2) Whereas the pH-dependence of $V_{\text {max. }}$ for the type I enzyme is consistent with a single ionizing group at the active site, this is not the case for the type II enzyme. The complex profile for the type II enzyme suggests that several ionizing groups may be involved. $V_{\max }$ for the type II enzyme increases rapidly from $\mathrm{pH} 6.3$ to 7.5, and then between $\mathrm{pH} 7.5-8.0$ and 8.2-9.0 two 

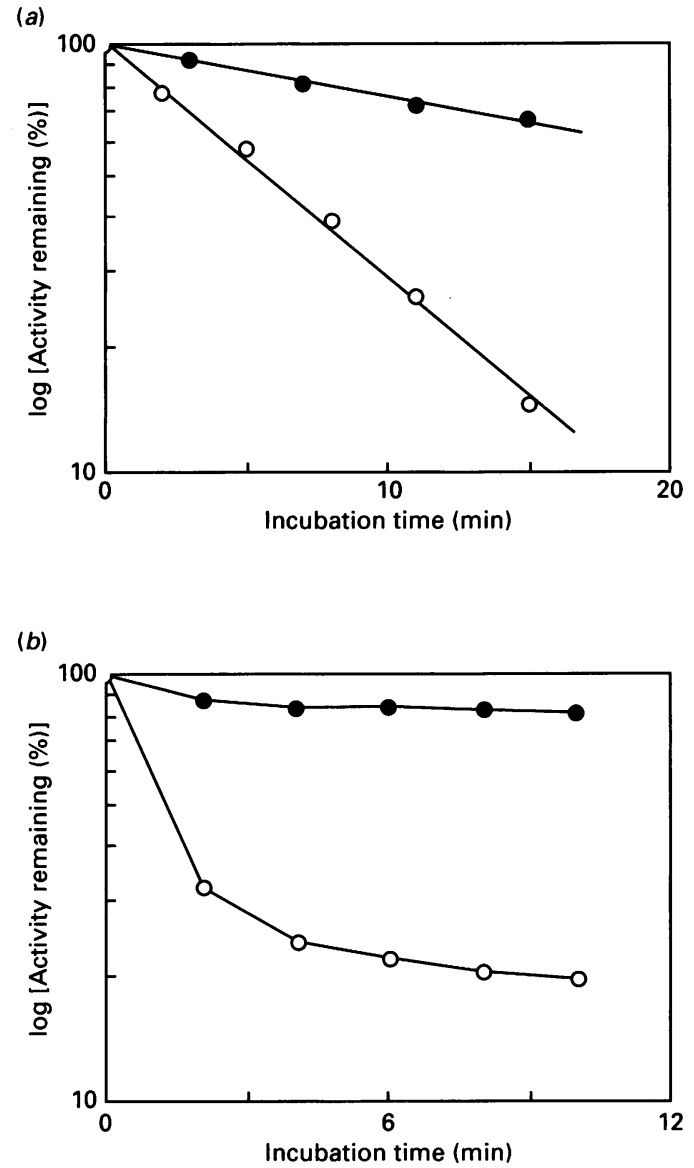

Fig. 6. DEP inactivations of type I ( $E$. coli) DHQase (a), and type II $(A$. nidulans) DHQase $(b)$ in the absence $(O)$ and presence $(O)$ of ligand

The concentration of DEP was the same in both sets of experiments (1 mM). Type I experiments were performed in potassium phosphate buffer $(0.05 \mathrm{M}, \mathrm{pH} 6.0)$ at $25^{\circ} \mathrm{C}$ and the type II experiments were performed in sodium bicarbonate buffer $(0.05 \mathrm{M}, \mathrm{pH} 8.5)$ at $25^{\circ} \mathrm{C}$. The concentration of protecting ligand was saturating for both enzymes under these conditions $(0.75 \mathrm{~mm}$-dehydroquinate for the type I enzyme and $5 \mathrm{~mm}$-dehydroquinate for the type II enzyme).

'bumps' are evident. The triangular points represent repeats of that particular $\mathrm{pH}$ suggesting that, for example, the increase between $\mathrm{pH} 8.4$ and 8.5 is not an artifact.

Histidine modification. Type I (E. coli) [29] and type II ( $A$. nidulans) DHQase are very susceptible to inactivation by the histidine-modifying reagent DEP (Fig. 6). In both cases the inactivation is substantially protected by an equilibrium mixture of substrate and product suggesting that active-site residues have been modified. The kinetics of inactivation of the two types of DHQase differ, however; the type I enzyme follows pseudo-firstorder kinetics whereas the kinetics for the type II enzyme are more complex. The inactivation of the type I enzyme has been fully characterized (R. Deka, C. Kleanthous \& J. R. Coggins, unpublished work). The overall conclusions from the results presented in Fig. 6 suggest that histidine residues are likely to be present in the active sites of both types of DHQase.

Type I and type II DHQases are likely to function by different mechanisms. A characteristic feature of the type I DHQase catalytic mechanism (and this has been shown for both the $E$. coli enzyme and the type I domain of the $N$. crassa pentafunctional protein [35]) is the involvement of a Schiff's base (imine) intermediate. This intermediate is formed at a conserved lysine residue (Lys-170) and plays an important role as an electron sink in the mechanism. It is also thought to be, in part, responsible for the unusual stereochemistry of this elimination reaction [49] (the stereochemistry most commonly observed in such elimination reactions is trans whereas the stereochemistry for type I DHQase is syn [50]). The involvement of this intermediate is easily shown by the addition of sodium borohydride to enzyme bound with ligand, which results in the inactivation of the enzyme as the active-site imine is reduced to a stable secondary amine [35,51]. Attempts to show ligand-mediated borohydride inactivation of the type II enzyme from $A$. nidulans were unsuccessful in a variety of buffers and pHs. This observation is contrary to preliminary borohydride inactivations reported for the type II enzyme of $S$. coelicolor DHQase [26]. These experiments have been repeated with several different preparations of the $S$. coelicolor enzyme and the original result cannot be reproduced (G. Walker \& J. R. Coggins, unpublished work). The tentative conclusion from the results described in this paper and those for $S$. coelicolor is that type II DHQases do not function by a Schiff's base mechanism. This conclusion is further supported by previously published sequence comparisons of the type II enzymes from $A$. nidulans and $N$. crassa with that of $M$. tuberculosis [27]. If the type II enzymes did function by a Schiff's base intermediate, but were not susceptible to borohydride inactivation (for example, if the imine was inaccessible to the reducing agent), then it might be expected that they would retain a conserved lysine residue, as seen with the type I enzymes [35]. This is not the case. There are no conserved lysine residues in all three type II sequences, even though there is a reasonably high degree of sequence identity between them (39\%) [27]. This argument is strengthened by comparison of these sequences with that of the $S$. coelicolor type II sequence which has recently been determined (P. J. White, H. G. Nimmo, I. S. Hunter \& J. R. Coggins, unpublished work). This enzyme also has but one lysine residue which is not conserved amongst any of the type II sequences.

If the type II enzymes do not function by a Schiff's base mechanism, then what alternatives can be proposed? Further work is necessary to address this question directly but some clues can be taken from other enzyme systems that also require an initial proton abstraction followed by stabilization of a carbanion intermediate. For example, there are two classes of the fructosebisphosphate aldolase enzymes which solve the problem of carbanion stabilization in two different ways (for a discussion see, for example, ref. [52]): type I enzymes from higher plants and mammals utilize imine formation, in much the same way as the type I DHQase enzymes; type II aldolases from yeast and bacteria, on the other hand, utilize a bivalent metal ion to achieve this stabilization. This may be the case for the type II DHQase enzymes, although there is no evidence for the involvement of metal in the mechanism; for example, chelating agents such as EDTA do not inhibit the enzyme. Another route to stabilization of the postulated carbanion is a cluster of positively charged amino acid side chains, such as arginine residues. Apart from preliminary evidence for inactivation of the type II enzyme by the arginine-specific reagent, phenylglyoxal (results not shown), there are no other data to suggest that this is the case. One further point is worthy of note concerning the apparent absence of imine formation in the type II enzymes. As outlined above, the formation of the Schiff's base has been seen as an important mechanistic contribution towards the unusual stereochemistry of the dehydration reaction catalysed by $E$. coli type I DHQase [49]. It will be of interest therefore to determine the stereospecificity of the type II enzymes, which do not seem to involve imine intermediates, to ascertain if the stereospecificity of the protonabstraction step is the same as that observed for the type I enzymes. 
Table 3. Classification of type I and type II DHQases from different organisms

Key: $\mathrm{S}$, shikimate pathway; $\mathrm{Q}$, quinate pathway. The sequence identity is relative to the $E$. coli sequence for type I enzymes and relative to the $A$. nidulans sequence for type II. Heat stability is indicated by survival of $>90 \%$ of enzymic activity when heated to $70{ }^{\circ} \mathrm{C}$ for 10 min. Unless otherwise stated, the $K_{\mathrm{m}}$ was measured at $\mathrm{pH} 7.0$ and $25^{\circ} \mathrm{C}$.

\begin{tabular}{|c|c|c|c|c|c|c|c|}
\hline Organism & Pathway & Subunit $M_{\mathrm{r}}$ & $\begin{array}{c}\text { Sequence } \\
\text { identity } \\
(\%)\end{array}$ & $\begin{array}{l}\text { Number of } \\
\text { subunits }\end{array}$ & $\begin{array}{c}K_{\mathrm{m}}^{\mathrm{DHQ}} \\
(\mu \mathrm{M})\end{array}$ & $\begin{array}{c}\text { Heat } \\
\text { stability }\end{array}$ & Reference \\
\hline \multicolumn{8}{|l|}{ Type I enzymes } \\
\hline E. coli & $\mathrm{S}$ & 27466 & 100 & 2 & 15 & No & This work and [29], [35] \\
\hline Salmonella typhimurium & $S$ & 27706 & 69 & - & - & - & [53] \\
\hline$N$. crassa & $\mathbf{S}$ & - & - & $2 \dagger$ & 5 & No & [13], [14] \\
\hline A. nidulans & $\mathbf{S}$ & $25600^{*}$ & 17 & - & - & No & [23] \\
\hline S. cerevisiae & $\mathbf{S}$ & $26377^{*}$ & 21 & - & - & No & [16] \\
\hline \multicolumn{8}{|l|}{ Type II enzymes } \\
\hline A. nidulans & $\mathrm{Q}$ & 16500 & 100 & 12 & 150 & Yes & This work and [3], [25] \\
\hline$N$. crassa & $\mathrm{Q}$ & 18500 & 67 & 12 & 70 & Yes & [44], [54] \\
\hline M. tuberculosis & $\mathrm{S}$ & 14000 & 28 & - & - & Yes & [27] \\
\hline S. coelicolor & $\mathbf{S}$ & 16000 & - & 12 & $650 \ddagger$ & Yes & [26] \\
\hline
\end{tabular}

* These values are estimates on the basis of optimal sequence alignments of the $E$. coli sequence with the equivalent domain within the pentafunctional protein which contains the five central activities of the shikimate pathway (see the Introduction).

$\dagger$ The pentafunctional protein of $N$. crassa is known to be dimeric although this may not reflect the oligomeric structure of the DHQase domain itself.

$\ddagger$ Determined at $37^{\circ} \mathrm{C}$ and $\mathrm{pH} 8.0$.

\section{Criteria for the classification of DHQase enzymes}

The present study, combined with the published work of others, forms the basis for a more comprehensive classification of type I and type II DHQases (Table 3). Thorough comparisons of the two classes are hampered by the fact that three of the best known type I enzymes (all from eukaryotes) are part of a pentafunctional protein and are not easily studied in isolation. In general, type I enzymes have a subunit $M_{\mathrm{r}} 10000$ greater than the type II enzymes and do not form large aggregate structures, although the information on the oligomeric structure of other type I enzymes is limited. It is important to note that enzymes within a class show significant sequence identity with each other but there is no evidence for substantial sequence identity between classes. Recent chemical modification data [41], however, have suggested the possibility of a common dehydroquinate-binding motif for the two types. Although information is limited, type I enzymes tend to have lower $K_{\mathrm{m}}$ values for dehydroquinate than the type II enzymes and, whereas all type II enzymes are thermostable, the type I enzymes are not. The type I enzyme from $E$. coli and the type II enzyme from $A$. nidulans are the best studied enzymes of their class and, on comparison with the other members of their class, are clearly representative examples of the two types of DHQase.

\section{Conclusions}

The dehydration of dehydroquinate to dehydroshikimate can be catalysed by two different DHQases (types I and II) which are characterized by proteins of different primary sequences, subunit size and thermodynamic stability. To date, type II DHQases have been found in both biosynthetic and catabolic pathways but type I enzymes have only been identified in biosynthetic pathways. This study has initiated a comparison of the mechanistic and biophysical properties of the two types of DHQase, a type I enzyme from $E$. coli and a type II enzyme from $A$. nidulans. The biophysical data unambiguously show that the type I enzyme from $E$. coli is predominantly a dimer whereas the type II enzyme is dodecameric and that their thermal and chemical denaturation profiles reflect the differing levels of quaternary structure. The absence of sodium borohydride inactivation of the type II enzyme along with sequence comparisons with other type II enzymes suggests that this class of DHQases, unlike the type I enzymes, may not function by a Schiff's base mechanism. Work is required to define the mechanism by which the type II enzymes stabilize the postulated carbanion intermediate in the reaction pathway.

The authors gratefully acknowledge the technical assistance of John Greene and thank Dr. S. Provencher for supplying the CONTIN program. This work was supported by the Science and Engineering Research Council of Great Britain.

\section{REFERENCES}

1. Haslam, E. (1974) The Shikimate Pathway, Butterworths, London

2. Giles, N. H., Case, M. E., Baum, J. A., Geever, R. F., Huiet, L., Patel, V. B. \& Tyler, B. M. (1985) Microbiol. Rev. 49, 338-358

3. Hawkins, A. R., Giles, N. H. \& Kinghorn, J. R. (1982) Biochem. Genet. 20, 271-286

4. Grant, S., Roberts, C. F., Lamb, H. K., Stout, M. \& Hawkins, A. R. (1988) J. Gen. Microbiol. 134, 347-358

5. Lamb, H. K., Hawkins, A. R., Smith, M., Harvey, I. J., Brown, J., Turner, G. \& Roberts, C. F. (1990) Mol. Gen. Genet. 223, 17-23

6. Hawkins, A. R., Lamb, H. K., Smith, M., Keyte, J. M. \& Roberts, C. F. (1988) Mol. Gen. Genet. 214, 224-231

7. Whittington, H. A., Grant, S., Roberts, C. F., Lamb, H. K. \& Hawkins, A. R. (1987) Curr. Genet. 12, 135-139

8. Beri, R. K., Whittington, H. A., Roberts, C. F. \& Hawkins, A. R. (1987) Nucleic Acids Res. 19, 7991-8001

9. Kinghorn, J. R. \& Hawkins, A. R. (1982) Mol. Gen. Genet. 186, 145-152

10. Charles, I. G., Keyte, J. W., Brammar, W. J. \& Hawkins, A. R. (1985) Nucleic Acids Res. 13, 8119-8128

11. Charles, I. G., Keyte, J. W., Brammar, W. J., Smith, M. \& Hawkins, A. R. (1986) Nucleic Acids Res. 14, 2201-2213

12. Lamb, H. K., Bagshaw, C. R. \& Hawkins, A. R. (1991) Mol. Gen. Genet. 227, 187-196

13. Lumsden, J. \& Coggins, J. R. (1977) Biochem. J. 161, 599-607

14. Gaertner, F. H. \& Cole, K. W. (1977) Biochem. Biophys. Res. Commun. 75, 259-264

15. Coggins, J. R., Boocock, M. R., Chaudhuri, S., Lambert, J. M., Lumsden, J., Nimmo, G. A. \& Smith, D. D. S. (1986) Methods Enzymol. 142, 325-341 
16. Duncan, K., Edwards, M. \& Coggins, J. R. (1987) Biochem. J. 246, 375-386

17. Millar, G. \& Coggins, J. R. (1986) FEBS Lett. 200, 11-17

18. Duncan, K., Chaudhuri, S., Campbell, M. S. \&Coggins, J. R. (1986) Biochem. J. 238, 475-483

19. Anton, I. A. \& Coggins, J. R. (1988) Biochem. J. 249, 319-326

20. Millar, G., Lewendon, A., Hunter, M. G. \& Coggins, J. R. (1986) Biochem. J. 237, 427-437

21. Duncan, K., Lewendon, A. \& Coggins, J. R. (1984) FEBS Lett. 170, 59-63

22. Coggins, J. R., Duncan, K., Anton, I. A., Boocock, M. R., Chaudhuri, S., Lambert, J. M., Lewendon, A., Millar, G., Mousdale, D. M. \& Smith, D. S. S. (1987) Biochem. Soc. Trans. 15, 754-759

23. Hawkins, A. R. (1987) Curr. Genet. 11, 491-498

24. Hawkins, A. R. \& Smith, M. (1991) Eur. J. Biochem. 196, 717-724

25. Da Silva, A. J. F., Whittington, H. W., Clements, J., Roberts, C. \& Hawkins, A. R. (1986) Biochem. J. 240, 481-488

26. White, P. J., Young, J., Hunter, I. S., Nimmo, H. G. \& Coggins, J. R. (1990) Biochem. J. 265, 735-738

27. Garbe, T., Servos, S., Hawkins, A. R., Young, D., Dougan, G. \& Charles, I. G. (1991) Mol. Gen. Genet. 228, 385-392

28. Grewe, R. \& Haendler, H. (1968) Biochem. Prep. 12, 21-26

29. Chaudhuri, S., Lambert, J. M., McColl, L. A. \& Coggins, J. R. (1986) Biochem. J. 239, 699-704

30. Beri, R. K., Grant, S., Roberts, C. F., Smith, M. \& Hawkins, A. R. (1990) Biochem. J. 265, 337-342

31. Kleanthous, C., Reilly, M., Cooper, A., Kelly, S., Price, N. C. \& Coggins, J. R. (1991) J. Biol. Chem. 266, 10893-10898

32. Provencher, S. W. \& Glockner, J. (1981) Biochemistry 20, 33-37

33. Nozaki, Y. (1972) Methods Enzymol. 26, 43-50

34. van Holde, K. E. (1985) Physical Biochemistry, 2nd edn., p. 117, Prentice-Hall, Englewood-Cliffs, NJ

35. Chaudhuri, S., Duncan, K., Graham, L. D. \& Coggins, J. R. (1991) Biochem. J. 275, 1-6

Received 5 June 1991/14 August 1991; accepted 28 August 1991
36. Perkins, S. J. (1986) Eur. J. Biochem. 157, 169-180

37. Harding, S. E. \& Johnson, P. (1985) Biochem. J. 231, 543-547

38. Creeth, J. M. \& Harding, S. E. (1982) J. Biochem. Biophys. Methods 7, 25-34

39. Rowe, A. J., Wynne-Jones, S., Thomas, D. \& Harding, S. E. (1989) Proc. SPIE Int. Soc. Opt. Eng. 1163, 138-148

40. Harding, S. E. (1984) Biochem. J. 219, 1061-1064

41. Kleanthous, C., Campbell, D. G. \& Coggins, J. R. (1990) J. Biol. Chem. 265, 10929-10934

42. Chang, C. T., Wu, C.-S. C. \& Yang, J. T. (1978) Anal. Biochem. 91, 13-31

43. Siegel, J. R., Steinmetz, W. E. \& Long, G. L. (1980) Anal. Biochem. 104, 160-167

44. Hautala, J. A., Jacobson, J. W., Case, M. E. \& Giles, N. H. (1975) J. Biol. Chem. 250, 6008-6014

45. Creighton, T. E. (1990) Biochem. J. 270, 1-16

46. Kleanthous, C. \& Coggins, J. R. (1990) J. Biol. Chem. 265, 1093510939

47. Gilbert, L. M. \& Gilbert, G. A. (1961) Nature (London) 192, 1181

48. Tanford, C. (1961) Physical Chemistry of Macromolecules, chapter 6, J. Wiley \& Sons, New York

49. Walsh, C. (1979) Enzymatic Reaction Mechanisms, Freeman, San Francisco

50. Hanson, K. R. \& Rose, I. A. (1963) Proc. Natl. Acad. Sci. U.S.A. 50, 981-988

51. Butler, R. J., Alworth, W. L. \& Nugent, M. R. (1974) J. Am. Chem. Soc. 96, 1617-1618

52. Price, N. C. \& Stevens, L. (1986) Fundamentals of Enzymology, Oxford University Press, Oxford

53. Servos, S., Chatfield, S., Hone, D., Levine, M., Dimitriadis, G., Pickard, D., Dougan, G., Fairweather, N. \& Charles, I. (1991) J. Gen. Microbiol. 137, 147-152

54. Geever, R. F., Huiet, L., Baum, J. A., Tyler, B. M., Patel, V. B., Rutledge, B. J., Case, M. E. \& Giles, N. H. (1989) J. Mol. Biol. 207, 15-34 